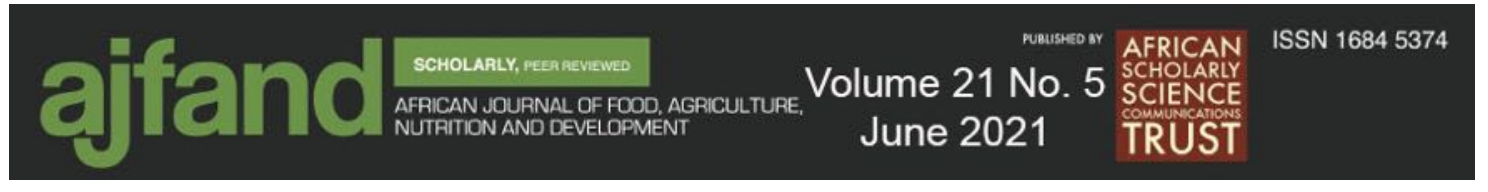

Afr. J. Food Agric. Nutr. Dev. 2021; 21(5): 17989-18004 Thttps://doi.org/10.18697/ajfand.100.19990

\title{
ADOPTION OF GARDEN COFFEE PRODUCTION TECHNOLOGY PACKAGE BY SMALLHOLDER FARMERS IN ETHIOPIA
}

Kassahun $\mathbf{T}^{1 *}$

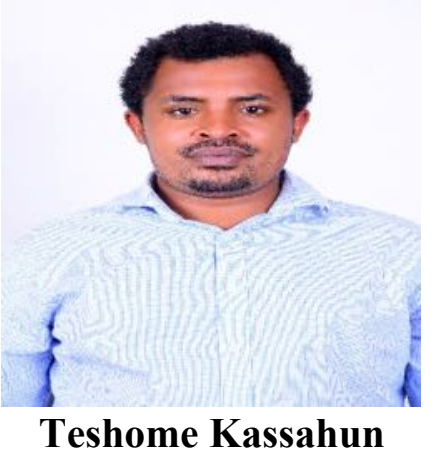

*Corresponding author email: teshe.kas@,gmail.com

${ }^{1}$ Department of Agribusiness and Value Chain Management; Hawassa University, Hawassa, Ethiopia, P.O. Box 05 


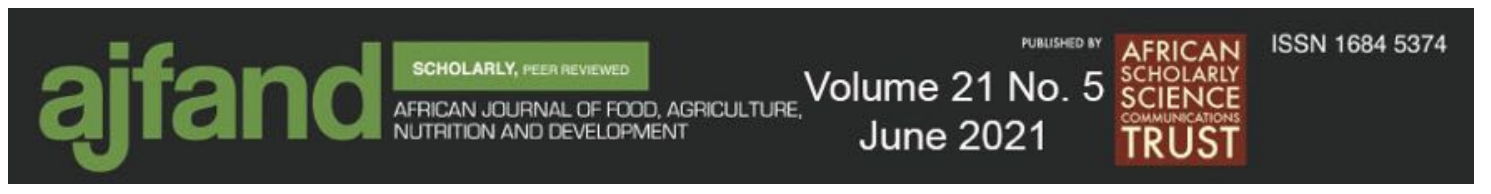

\begin{abstract}
This study investigated the level and determinants of garden coffee production technology package adoption in Ethiopia. The analysis was based on survey data collected from 293 garden coffee-growing households. The findings show that garden coffee production technology package adoption status in Dale districts was various across the smallholders' growers. The productivity of improved coffee varieties at farm plots was less than at research plots in Dale due to low coffee production technology package adoption. The use of improved coffee varieties, weed control practices, compost application, pruning practices, shade tree management, intercropping practices, and coffee seedling planting spacing is the main garden coffee production technology package practiced by smallholder coffee growers in Dale. Thus, the garden coffee production technology package adoption index score ranged from 0.43 to 1.00. Adoption index scores were categorized into high ( 0.71 to 1$)$, medium $(0.5$ to 0.7$)$ and Low ( 0.43 to 0.49$)$ adopters. Only $57 \%$ of farmers reached high coffee production technology adoption status but the remaining $30 \%$ and $13 \%$ of garden coffee farmers attained medium and low adoption status. The mean adoption index score was found to be 0.66 , which implies the overall adoption status was found under the medium technology adoption category. The maximum likelihood estimates of Tobit model result shows that gender of household head (-0.261), education level (0.09), the annual income of the household (0.003), farm size (0.031), availability of labor $(0.155)$, credit facilities (0.087), coffee extension services (0.047) and farmer perception of improved coffee varieties $(-0.024)$ were significant determinants of garden coffee production technology package in Dale district. Hence, for farmers to adopt new technology they must know it well. Adopting all components of the coffee production technology package simultaneously as recommended by the research center enhances coffee productivity at farm plots level. Moreover, building better coffee production extension services, institutional arrangement, and access to new technology information can possibly increase coffee production technology package adoption in Ethiopia.
\end{abstract}

Key words: production technology package adoption, smallholders, garden coffee farmers, Dale 


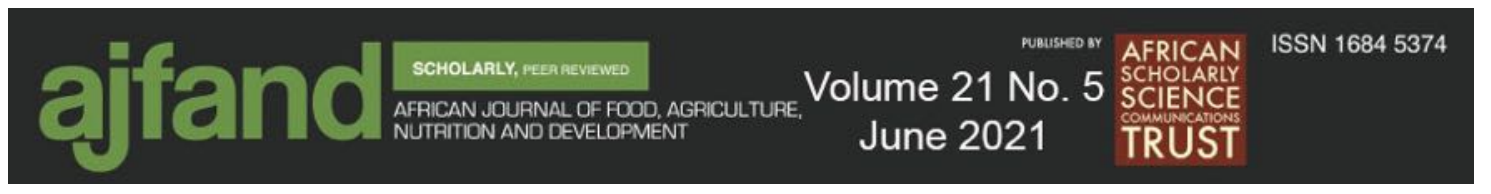

\section{INTRODUCTION}

The coffee plantation is an important strategy for building up the system of resilience through improved biodiversity and ecosystem services. It requires very specific environmental conditions for successful production, depending on the coffee variety grown [1]. Two coffee types in the world, Arabica and Robusta coffee represent 70\% and $30 \%$ of global coffee production [2]. Coffee is the world's second most traded agricultural commodity next to petroleum [3]. More than 70 countries produce coffee, but the overwhelming majority of the supply comes from Brazil, Vietnam, Colombia, Indonesia, Honduras, Ethiopia, and India. Brazil, the top coffee producing country, accounted for $40 \%$ of the global coffee supply, while Vietnam is the second-largest coffee producer, accounting for roughly $20 \%$ of the world coffee production [3]. Coffee producers in Africa accounted for about $12 \%$ of global supply and less than $11 \%$ of global exports of the product. Eastern Africa, the origin and a pronounced exporter of coffee for centuries is perhaps a popular coffee region and accounts for 1.41 million tons of production per year [4].

In terms of production and marketing of coffee beans, Ethiopia is the largest producer of coffee in sub-Saharan Africa and is the fifth-largest coffee producer in the world [5]. The coffee agribusiness sector has also huge opportunities for income generation, poverty alleviation, and employment in Ethiopia. Moreover, it is the driving force of the economy, ecology, and socio-cultural life of people; and about 5.2 million households have participated in coffee production activities; and over 25 million people ( $25 \%$ of Ethiopian population) are engaged in coffee production, distribution, trading, processing, exporting and other support and downstream activities [6]. Coffee farming in Ethiopia takes place over a vast area and under a wide variety of production systems and various growing condition, with many different farming systems, including forest coffee, semi-forest coffee, garden coffee, and modern coffee plantation which account for $10 \%, 35 \%, 50 \%$, and $5 \%$, respectively of total production [7]. The major coffee production areas and categories in Ethiopia include Harar coffee, Yirgacheffe coffee, Limmu coffee, Sidama coffee, Lekempti coffee, Bebeka/Tepi coffee, and Jimma coffee. This indicates that the country produces large volumes of coffee beans every year and most of the supply comes from garden coffee farming. Garden coffee is normally found in the vicinity of a farmer's residence. But, there are too few coffee production upgrading systems and new technology adoption by smallholder farmers. These conditions have been contributing negative impact on value addition and productivity of the coffee sector in Ethiopia.

Among others, the Sidama region has well-known in the production of the garden (cottage coffee). Therefore, this study aimed to investigate the extent and determinants of adoption of garden coffee production technology packages by smallholder farmers in the Dale District of Sidama region. Dale is well-known in garden coffee production, but productivity per hectare and quantity of coffee bean supply to the market has been decreasing due to low adoption of garden coffee production technology package. Adoption studies can be useful to provide information and helpful feedback from farmers and help in refining the technology generation and dissemination efforts, and to assess the effectiveness of a technology transfer strategy and improve the flow of 


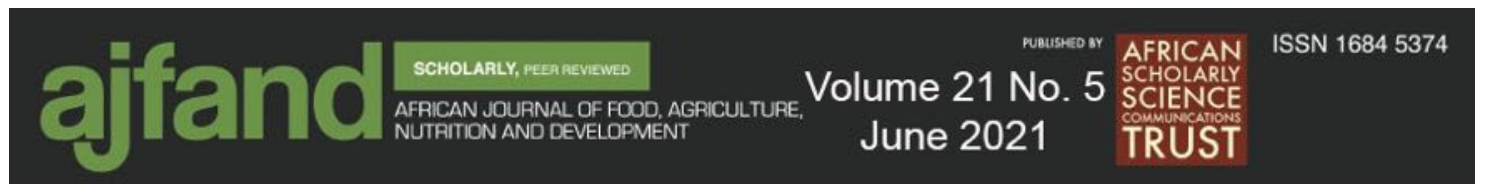

information between research and extension on the one hand, and policymakers on the other.

\section{MATERIALS AND METHODS}

A cross-sectional survey research design was adopted. Both primary and secondary data sources are used in this paper. Primary data were collected from 293 garden coffee-growing households by using a semi-structured questionnaire. The secondary data on garden coffee production technology package standards was obtained from Southern Nation Nationalities and People's Regional state Agricultural Bureau. The coffee production technology package recommended by Jimma Agricultural Research Center in 2007 used as technology package standards. Information about improved coffee varieties was obtained from Development Agents (DA) in the Dale District. The sample size was determined by using Yamane [8] formula by considering a 95\% confidence label. The sampling was carried out by using a multi-stage sampling method. First, through vetting with regional coffee and tea experts, among 14 coffee growing districts in the Sidama region, Dale District was selected due to the existing large garden coffee production performance. Third, out of 1099 total target population, a sample of 293 garden coffee farmer households were selected from each kebele randomly based on proportional to the population size because numbers of existing coffee growers varied from kebele to kebele (Table 1).

Descriptive statistics and econometric methods of data analysis used to generate information and address the objectives of the study. The Two-limit Tobit model used to identify the determinants of farmers' adoption of garden coffee production technology package at selected garden coffee potential kebeles (small village). Censored regression models are usually estimated by the Maximum Likelihood (ML) method. The loglikelihood function is specified with an assumption that the error term $\varepsilon$ follows a normal distribution with mean 0 and variance $\sigma 2$. The Tobit coefficients can be interpreted as coefficients of a linear regression model. In line with this, the determinants of adoption of garden coffee production technology packages were investigated by using the Tobit model. The equation for the model is constructed as:

$Y^{*}=X_{i} \beta_{i}+\varepsilon_{i}$

Where $\mathrm{Y}^{*}$ is unobserved for values less than 0 and greater than 1 (called a latent variable). It represents an index for garden coffee technology package adoption; $\mathrm{X}_{\mathrm{i}}$ represents a vector of explanatory variables, $\beta_{i}$ is a vector of unknown parameters, and $\varepsilon_{\mathrm{i}}$ is the error term. The 0 values indicated non-adopters; and 1 value represents the full adopters of the technology. The value between 0 and 1 indicates the level of the adoption within the range of the Tobit model limit.

Assume yi as the observed dependent variable, the two limit Tobit model can be specified as:

$$
y_{i}=\left\{\begin{array}{c}
0 \quad \text { if } y_{i}^{*} \leq 0 \\
y^{*} \text { if } 0<y_{i}^{*}<1 \\
1 \quad \text { if } y_{i}^{*}>1
\end{array}\right\}
$$




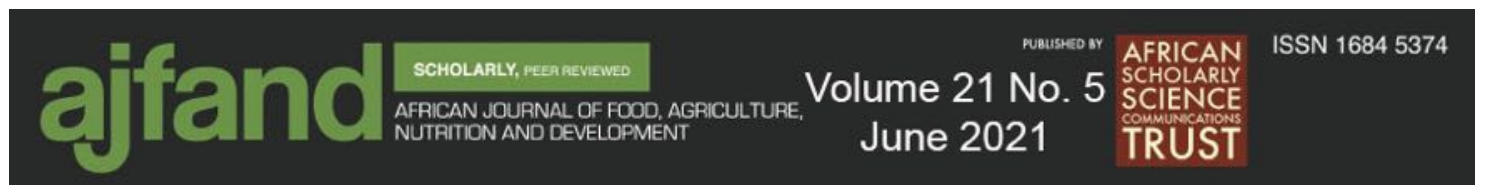

Accordingly, a garden coffee production technology adoption index value ranged from 0 to 1 . A value of 0 indicates non-adopter; a value 1 represents the full adopter of the technology component (adopted without discontinuity). Therefore, the adoption index values between 0 and 1 indicate the level of the adoption that means the current status of adoption and intensity of use of garden coffee technology package. In this specific study, the dependent variable was garden coffee production technology adoption index which was computed from the use and intensity of garden coffee production technologies including improved varieties, weeding, compost application, pruning, shade tree, intercropping and spacing in garden coffee production. The index was computed based on garden coffee production technology package standards (Table $4 \&$ 5). If the individual smallholder garden coffee farmer's technology adoption met the recommended standards for each technology package, it received the value 1, otherwise it received the value $0 \mathrm{~s}$. The Garden coffee production technology adoption index was specified as follows:

$$
G C A I_{i}=\frac{I V+W+C A+P+S T+I C+S P}{7}
$$

Where $\mathrm{GCAI}_{\mathrm{i}}=$ Garden coffee production technology package adoption index of the $\mathrm{i}^{\text {th }}$ smallholder garden coffee farmer, IV denotes the improved coffee varieties used by the $\mathrm{i}^{\text {th }}$ farmer which takes the value 1 if farmer used any improved coffee varieties distributed from research center, otherwise 0); W, CA, P, ST, IC, SP also denotes weeding, compost application, pruning, shade tree, intercropping, spacing, respectively and measured a value 1 if the $i^{\text {th }}$ farmer adoption meet the recommended garden coffee production technology package standards, otherwise measured as a value 0 .

\section{Research ethics}

Hawassa University has research module team under each department level. To conduct this research in an ethical way, formal procedures were followed to collect data from the concerned organizations. First, the research proposal was presented to the research team and obtained approval letters for further field work in study area. Second, the respondents were made aware of the objectives of the study and that consent was needed for their participation. Third, de-identified data were used. Fourth, fair and accurate reporting of findings was done. Using others works properly acknowledged. Finally, the privacy, confidentiality and anonymity of the respondents were totally to be respected, plus no part of the respondent's response is used for any other purpose than this single study.

\section{RESULTS AND DISCUSSION}

\section{Garden coffee production technology package adoption status}

The major garden coffee technology components such as improved varieties, weeding, compost application; pruning, shade tree, intercropping, and spacing are the focus of the study. Each technology component was recorded as a nominal measurement level and the overall adoption measured as a weighted adoption index. Accordingly, smallholder garden coffee farmers who were meeting the recommended garden coffee production technology package standards by the agricultural research center in Ethiopia 


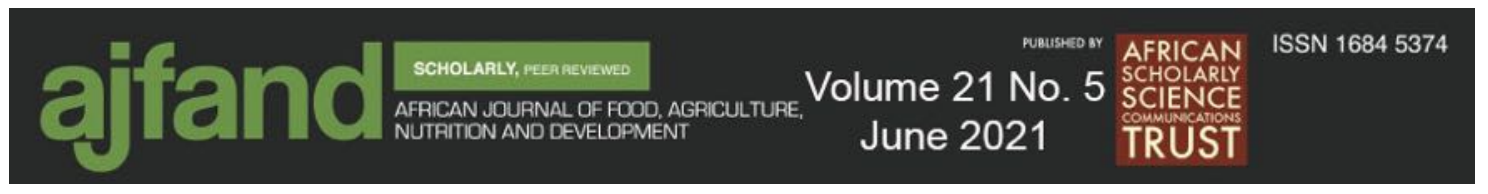

are consider as adopters and otherwise non-adopters (Table 3). The garden coffee production technology package adoption status in Dale District was computed and presented in Table 4. Overall adoption index score and status ranged from 0.43 to 1.00 . Accordingly, 39 smallholder garden coffee farmers' adoption status was low (0.43 to 0.49); 87 smallholder garden coffee farmers' adoption status was medium (0.5 to 0.7 ), and 167 smallholder garden coffee farmers were found to be high or full adopters.

Each coffee production technology package adoption status in the study area is described as follows. The overall adoption status of improved coffee varieties in the Dale district was low. Among the smallholder garden coffee farmers, 116 farmers used improved coffee varieties (74110, 74112, 74140, and Angafa (1377)) while 177 farmers were non-adopters i.e. use local coffee varieties. But, local coffee varieties were affected by coffee berry disease (CBD), and crop yield was dramatically decreased. Agriculture Research centers in Ethiopia confirmed that the uses of improved coffee varieties can resist CBD. Among improved coffee varieties, 74110, 74112, 74140, and Angafa (1377) were widely grown in the Sidama region in general and Dale district in particular. However, the improved coffee varieties productivity at farm plots of 74110, 74112, 74140, and Angafa (1377) were 12.20, 11.60, 13.70, and 13.00 quintal/ha. The productivity of improved coffee varieties at farm plots was less than at research stations (Table 2).

Regarding weed control practices, $70 \%$ of garden coffee growers adopted weeding practice of three-rounds per year while the remaining respondents were weeding less than three rounds per year. Cultivation is done to loosen the compacted soil around the plant root while weeding is very important to avoid nutrient competition.

About compost application, $72 \%$ of garden coffee farmers met the recommended practices, for example, applied 10 kilograms of compost per single coffee tree per year. The farmers' overall adoption status of compost application was medium. The application of compost increases aeration and infiltration, reduces soil erosion, increases water holding capacity, increases soil CEC, supplies nutrients to the plants, including $\mathrm{N}, \mathrm{P}$, and $\mathrm{S}$, and buffers the soil against rapid changes in $\mathrm{pH}$ since the area dominated is with organic coffee certified farming system.

Out of total garden coffee growers, 91\% applied either heavy pruning (stumping) or light pruning practices. The farmers' overall adoption status of the pruning practice was high. The goal of pruning is to create well-structured healthy trees that give good cherry yields over a long period or to rejuvenate old trees by stumping. Pruning avoids unnecessary competition for nutrients by removing unproductive wood; removes weak branches that will not yield at all or only a little; avoids high humidity and fungus development through better air circulation; creates better access to the core of the tree when spraying pesticide, and decreases the risk of damage to the coffee trees' canopy during periods of heavy rain and/or wind.

Out of total garden coffee growers, $55 \%$ of farmers have adopted either temporary or permanent shade on a garden coffee farm. But, many garden coffee farmers were growing coffee without shade or had not adopted shade tree management. The farmers' 


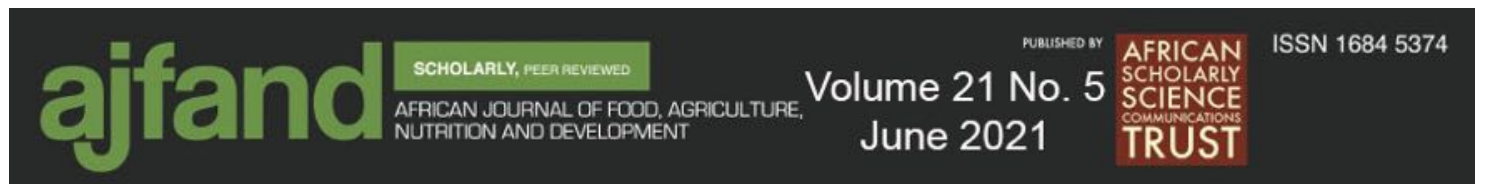

overall adoption status of shade tree management was medium. The coffee tree requires shade tree management. Coffee is growing in the lower canopy layer of the forest and receives a lot of shade. Temporary shade is provided by fast-growing, short-lived trees. The permanent shade is provided by long-lived trees. Several species can be used for shadow. The main consideration is that the species used are leguminous and that the root system penetrates either very deep or is not very extensive to avoid excessive competition for water and nutrients with the coffee. The farmers' overall adoption status of shade tree management was medium.

Regarding intercropping, many coffee farmers intercrop their coffee with enset (false banana), cereal, vegetables, root, and fruit crops. But these crops are heavy feeders of soil nutrients that compete for the coffee tree. The recommended crop for intercropping is leguminous crops like haricot bean, peas, and pigeon pea. An advantage of these crops is that they improve soil fertility and provide additional income for the farmers.

Out of all garden coffee growers, $81 \%$ of producers fulfilled appropriate coffee tree planting spacing. The farmers' overall adoption status of coffee planting spacing was medium. To avoid nutrient competition, sufficient spacing between plants and rows is vital to get maximum yield in a given plot of land. Appropriate spacing enables the farmer to avoid over and under population in a given plot of land, which hurts yield. The suggested spacing for coffee production is $2 \times 2$ meters or 2500 coffee seedlings per hectare (Table 4).

\section{Determinants of garden coffee production technology package adoption}

The households' characteristics affecting farmers' decision to adopt an agricultural technology include farmer specific characteristics (age, sex, education status, and coffee farming experience), farm resources (annual income, farm size), institutional arrangements (access credit and accessed coffee production extension services). These summary statistics are presented in Tables $2 \& 3$, and results aligned with regression model outputs. However, regarding access to information, 55\% of households accessed coffee production technology package information, and $45 \%$ did not. Most farmers obtain new information through social activities. The maximum likelihood estimates of the Tobit Model result show that gender of household head, annual income, farm size, access to credit facilities, availability of coffee extension services, and dependency ratio significantly affected the farmers' adoption of garden coffee production technology package in Dale district (Table 5). Those determining factors of adoption of garden coffee production technology package are as follows.

Gender of household head was found negatively influencing the adoption of the garden coffee production technology. The result indicated that if the household head is female, the chances of adoption of garden coffee production technology package decrease by the factor of 0.261 as compared to a household headed by a male, and the result was statistically significant at a $10 \%$ level of significance. Out of garden coffee growers, $83.7 \%$ were male-headed households and the rest $16.3 \%$ were female-headed households. The majority of female household adopters were found in the low adoption category which indicates that they are less capable of adopting coffee production packages as compared to their male household counterparts. The result of this study is 


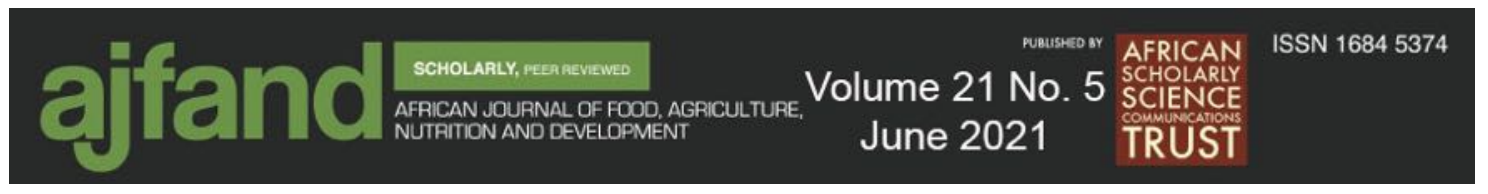

in agreement with the results of previous researchers who have reported the significant relationship between sex and adoption of agricultural technologies $[9,10]$. In most cases, male-headed households have better access to information on improved technologies and are more likely to adopt new technologies than females. Women farmers are often forgotten in official agricultural statistics. Because women play a key role in the agricultural system, adoption studies must consider the degree to which a new technology reaches women farmers. The women-headed households are usually less likely to adopt new technology since they are usually less endowed with resources and are less exposed to new information and ideas [11].

The education of household head represents the level of formal schooling completed by the household head at the time of the survey. The education level of the household head is one of the important indicators of human capital, has a positive and significant effect on the adoption of improved coffee variety at $1 \%$ level of significance, implying that the likelihood of garden coffee production technology package adoption increases with farmers' formal education level. On average, each additional year of education of the household head increases the probability that a farmer adopts the garden coffee production technology package, and then adoption index score increase by 0.09 units. Education enhances farmers' ability to perceive, interpret, and respond to new events. Education may make a farmer more receptive to advice from an extension agency or more able to deal with technical recommendations that require a certain level of skill. Providing training and technical extension services on coffee production to less educated smallholder farmers will increase the probability of crop growing technology adoptions in general and coffee production in particular. This finding aligned with different authors like Mulugeta, Sisay and Belay [10, 12, 13] who reported on maize, wheat, and coffee production technology adoptions, respectively in Ethiopia, who also revealed that education has a positive and significant relationship with the adoption and intensity of adoption technology.

Farm size in this particular study represents the amount of total plot size in hectares, which is owned by individual coffee growers. Most smallholder farmers in Dale district owned less than 1.5 hectares of plot and a small number of farmers owned sufficient farm size ( 2 to 3 hectares). Farm size has a positive and significant relationship with the adoption and intensity of adoption of coffee production technology packages and statistically significant at the $5 \%$ probability level. Hence, an increase in farm size by one hectare would lead to an increase in the likelihood of garden coffee production technology package adoption by a factor of 0.031 units (adoption index scores), keeping other factors constant. The result was also associated with Admassie and Ayele [11] who found that the resource base of the household could also be an important factor influencing the household's technology adoption behavior. Accordingly, coffee production technology adoption needs appropriate spacing, intensive management characteristics, and large farms.

Household annual income represents the amount of money in birr that farmers gain from their different economic activities. Livestock husbandry, off-farm activities, income from selling of coffee bean, and other crop cultivation are key sources of households' annual income. The average annual income of households was 19740 


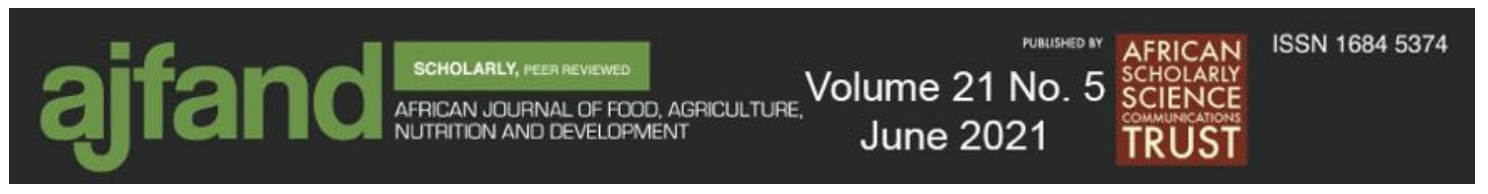

$(\$ 1 \mathrm{USD}=0.03 \mathrm{EBT})$ with a standard deviation of birr 7739.00. But, there was a significant mean annual income difference among the smallholder farmers in the study area. Coffee farmers with larger annual incomes are more likely to adopt a coffee production technology package than low annual income because purchasing improved coffee varieties and pruning tools requires an extra cash investment. The econometric analysis result for annual income shows that household annual income was among the determining factor of the adoption of garden coffee production technology packages in the study area. The result is statistically significant at $1 \%$ level. An increase in household annual income by one birr would lead to an increase in the likelihood of garden coffee production technology package adoption by a factor of 0.003 units. This agreed with Mulugeta [10] who reported on the adoption of old coffee stumping technology in Dale district, where on average, adopters had higher annual farm income than compared to non-adopters.

Availability of credit facility has a positive influence on the adoption of garden coffee production technology package, significant at the $1 \%$ level. Moreover, the model result shows that households with access to credit facilities are more likely to adopt the coffee technology package. An increase in access to credit facilities would lead to an increase in the likelihood of garden coffee production technology package adoption by a factor of 0.087 units. For the reason that access to credit may solve cash shortage problems to buy new coffee varieties, stumping and pruning tools, and cover labor costs. From this result, it can be stated that those farmers who have access to formal credit are more likely to adopt garden coffee production technology package than those who have no access to formal credit. So strengthening and expansion of credit institutions into rural areas is of paramount importance to address the credit needs of the farming community. The result of this study is in agreement with [14].

Coffee production extension services have a significant positive influence on the adoption of garden coffee production technology package, since for farmers to adopt a new technology they must know it. It is, therefore, important to examine the degree to which farmers have received the necessary extension service. Coffee production-related extension services such as supply of seed varieties and, providing training on coffee production technology packages improve the production and productivity of coffee tree growth and output. Coffee extension service has significantly influenced the likelihood of adoption of garden coffee production packages at less than a 5\% significance level. An increase in access to extension services would lead to an increase in the likelihood of garden coffee production technology package adoption by a factor of 0.047 units, keeping other factors constant. Contact with extension information sources, participation in extension events (training, field day participation and hosting demonstration) and social participation (types of social participation and number of social participation) were found to have a positive and significant relationship with adoption of old coffee stumping technology in Sidama, Ethiopia $[9,5]$

Farmers' perception of improved varieties price has significantly and negatively influenced the adoption of garden coffee production technology package. The attitude of farmers towards coffee technology was measured as whether improved varieties price was high or low. This means that farmers who perceived as improved coffee 


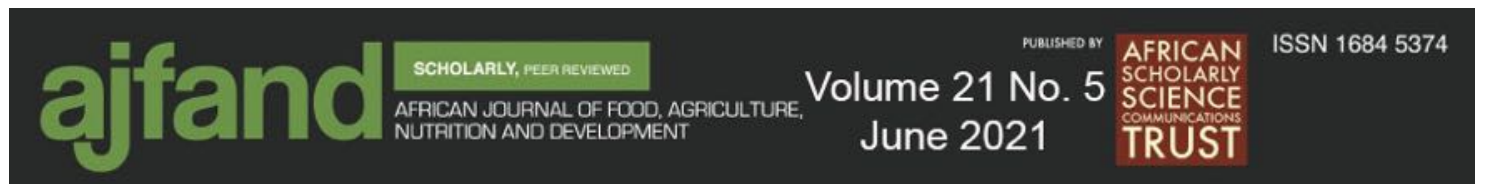

variety price is low were more likely to adopt coffee technology package than farmers who perceived the improved variety prices are high. Farmers' perception has negatively significantly influenced the probability and intensity of garden coffee technology package at a $1 \%$ level of probability. A decrease in perception of improved varieties price would lead to an increase in the likelihood of garden coffee production technology package adoption by a factor of 0.024 units. This result associated with Hailu [16] who demonstrated the impact of improved technology on productivity and found that low adoption of improved agricultural technologies was attributed to unavailability of technologies, high cost of required inputs, lack of access to and high interest on credit, and policies that discourage improved technology adoption such as the promotion of state farm in Ethiopia.

The dependency ratio has a significant positive influence on the adoption of garden coffee production technology packages at a $1 \%$ level of probability. An increase in the dependency ratio would lead to an increase in the likelihood of garden coffee production technology package adoption by a factor of 0.155 units. Increased production may also require an increased involvement of household members. Household size may be a proxy for labor availability within the household. But, increased inactive household size has a negative impact on the adoption of garden coffee production technology package, perhaps because inactive household size; causes smallholder farmers to allocate more of farm plots to seasonal crop production to fulfill food consumption. Also, Kidane [17] indicated that adopters of new wheat varieties were younger with a relatively larger average family size, more experienced in farming, higher average annual off-farm cash incomes, better size of livestock holding, and plough oxen, more frequent contact with development agents than the non-adopters.

\section{CONCLUSION}

The findings show that the productivity of improved coffee varieties at farm plots was less than research plots in Ethiopia due to the low adoption status of coffee production technology package by smallholder farmers. Adopting all components of the garden coffee production technology package simultaneously at a farm plot as recommended by the research center will enhance the productivity of coffee yields at the farm plot level. The low coffee production extension services, lack of access to new technology information, weak coffee value chain, and institutional arrangement are key determinants of coffee production technology package adoption in Ethiopia. The maximum likelihood estimates of Tobit model result show that the gender of household head, the annual income of the household, education level, farm size, availability of labor, availability of credit facility, coffee extension services; and farmer perception of improved coffee varieties price have a significant impact on the adoption of garden coffee production technology package in Dale district. Thus, there are huge economic opportunities for coffee growing countries to increase the quantity of coffee bean market supply and exports through addressing the determinants of garden coffee production technology package adoption. To use the external coffee demand opportunities at local, national, regional, and global in the present market, internal weakness on technology adoption and coffee value chain structure should be upgraded. Moreover, better extension services through projects should be established for 


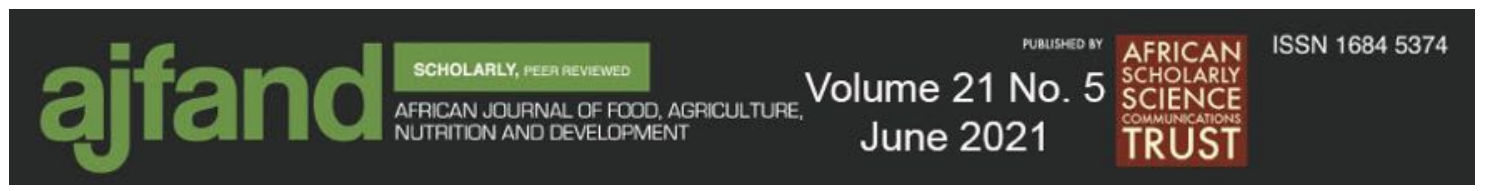

smallholder farmers on coffee production technology package adoption such as the use of improved coffee varieties, weed control practices, compost application, pruning practices, shade tree management, intercropping practices, and coffee planting spacing. Implementing these packages as recommended definitely will increase the coffee productivity and supply to the market in coffee-growing countries. 


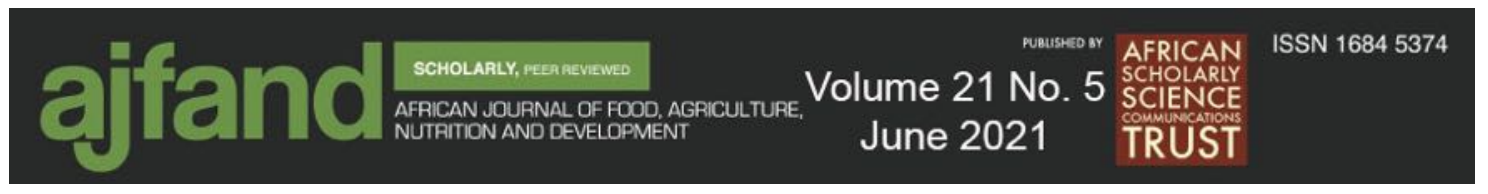

Table 1: Sample size distribution to the selected coffee potential kebeles

\begin{tabular}{|c|c|c|c|}
\hline $\begin{array}{c}\text { Selected garden coffee } \\
\text { potential Kebeles }\end{array}$ & $\begin{array}{c}\text { Total target } \\
\text { population }\end{array}$ & $\begin{array}{c}\text { Proportion of } \\
\text { population }\end{array}$ & Sample size \\
\hline Shafena & 217 & 0.20 & 59 \\
\hline Manche & 305 & 0.28 & 82 \\
\hline Duba & 255 & 0.23 & 67 \\
\hline Mutto & 322 & 0.29 & 85 \\
\hline Total & 1099 & 1 & 293 \\
\hline
\end{tabular}

Table 2: Coffee varieties productivity on research station versus farm plots

\begin{tabular}{|c|c|c|}
\hline \multicolumn{3}{|c|}{ Productivity quintal /ha } \\
\hline $\begin{array}{c}\text { Some varieties adopted } \\
\text { in Dale district }\end{array}$ & productivity on farm plots & $\begin{array}{c}\text { Productivity on research } \\
\text { station }\end{array}$ \\
\hline 74110 & 12.2 & 19.1 \\
\hline 74112 & 11.6 & 18.1 \\
\hline 741140 & 13.7 & 19.7 \\
\hline Angafa (1377) & 13.0 & 20.4 \\
\hline 741 & - & 12.2 \\
\hline 7440 & - & 18.2 \\
\hline 74165 & - & 17.3 \\
\hline 74148 & - & 18 \\
\hline
\end{tabular}

Source: own survey (productivity on farm plots) and secondary data from Jimma Agricultural Research Center

\section{Table 3: Garden coffee production technology package standards}

\begin{tabular}{|l|l|}
\hline $\begin{array}{l}\text { Technology package } \\
\text { components }\end{array}$ & \multicolumn{1}{|c|}{ Recommended } \\
\hline $\begin{array}{l}\text { Use of improved coffee } \\
\text { varieties }\end{array}$ & $\begin{array}{l}\text { Use of research released new coffee varieties include } \\
74110,741,7440,741140,74165,74112,74148 \text { and } \\
\text { Angafa (1377) }\end{array}$ \\
\hline Weed control practices & Weeding practice three rounds per year \\
\hline Compost application & 3-5kg/tree/ two rounds per year \\
\hline Pruning practices & $\begin{array}{l}\text { Either light and heavy pruning, for stumping (tree height } \\
40 \text { centimeter }\end{array}$ \\
\hline Shade tree management & Both temporary and permanent shade trees \\
\hline Intercropping practices & Either leguminous crops or enset (false banana) \\
\hline Coffee planting spacing & 2x2m or 2500 trees/hectare \\
\hline
\end{tabular}

Source: Secondary data source from Jimma Agricultural Research Center 


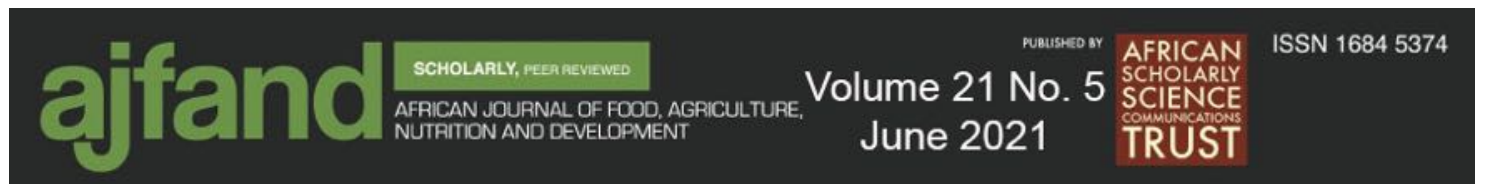

Table 4: Garden coffee production technology package adoption status in Dale district

\begin{tabular}{|c|c|c|c|c|}
\hline \multirow[t]{2}{*}{$\begin{array}{l}\text { Technology package } \\
\text { components }\end{array}$} & \multicolumn{2}{|c|}{$\begin{array}{l}\text { Smallholder garden coffee } \\
\text { farmers }(\mathrm{N}=293)\end{array}$} & \multirow[t]{2}{*}{$\begin{array}{l}\text { Proportion of } \\
\text { adopters }\end{array}$} & \multirow[t]{2}{*}{$\begin{array}{l}\text { Each component } \\
\text { adoption status }\end{array}$} \\
\hline & Adaptors & Non-adopters & & \\
\hline $\begin{array}{l}\text { Use of improved } \\
\text { varieties }\end{array}$ & 116 & 177 & 0.40 & Low \\
\hline Weed control practices & 204 & 89 & 0.70 & Medium \\
\hline Compost application & 211 & 82 & 0.72 & High \\
\hline Pruning practices & 267 & 26 & 0.91 & High \\
\hline $\begin{array}{l}\text { Shade tree } \\
\text { management }\end{array}$ & 162 & 131 & 0.55 & Medium \\
\hline Intercropping practices & 150 & 143 & 0.51 & Medium \\
\hline $\begin{array}{l}\text { Coffee planting } \\
\text { spacing }\end{array}$ & 238 & 55 & 0.81 & High \\
\hline $\begin{array}{l}\text { Overall adoption index } \\
\text { score and status }\end{array}$ & \multicolumn{4}{|c|}{$\begin{array}{ll}\text { Adopter categories } \\
\text { - } & \text { Adoption index score range }=0.43 \text { to } 1.00 \\
\text { - } & \text { Low }=0.43 \text { to } 0.49 \text { (number of low adopter smallholder } \\
& \text { garden coffee farmers }=39 \text { ) } \\
\text { - } & \text { Medium }=0.5 \text { to } 0.7 \text { (number of medium adopter } \\
& \text { smallholder garden coffee farmers }=87 \text { ) } \\
\text { - } & \text { High }=0.71 \text { to } 1 \text { (number of high adopter smallholder } \\
& \text { garden coffee farmers }=167 \text { ) }\end{array}$} \\
\hline
\end{tabular}




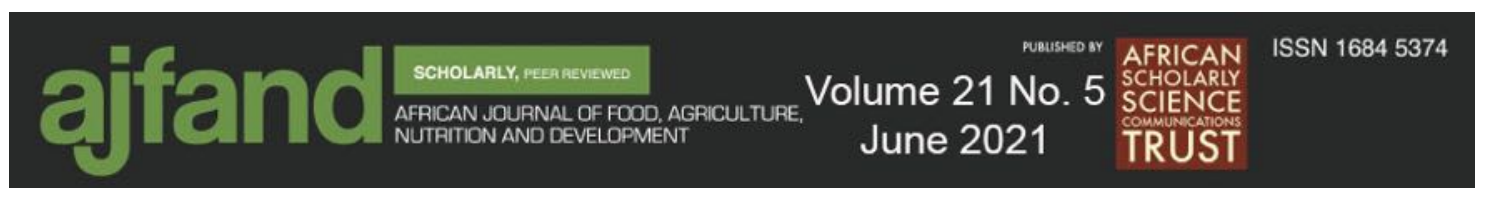

Table 5: Determinants of farmers' adoption of garden coffee production technology package: Maximum Likelihood Estimates of Tobit Model

\begin{tabular}{|c|c|c|c|}
\hline Variables & Coefficient ( B) & Standard Error (SE) & t-ratio \\
\hline Age of household head (in years) & 0.0011 & 0.001 & 1.46 \\
\hline Gender of household head (Male or Female) & $-0.261^{*}$ & 0.073 & -3.56 \\
\hline Education level (in numbers of schooling) & $0.09^{* * *}$ & 0.031 & 2.88 \\
\hline Household size & -0.002 & 0.025 & -0.79 \\
\hline Experiences in garden coffee farming & 0.004 & 0.009 & 0.40 \\
\hline Annual income ('000’ Birr) & $0.003 * * *$ & 0.09 & 3.31 \\
\hline Farm size (in hectare) & $0.031 * *$ & 0.0136 & 2.25 \\
\hline Availability of credit facility (yes/no) & $0.087 * * *$ & 0.022 & 4.02 \\
\hline Coffee production extension services (yes/no) & $0.047 * *$ & 0.028 & 2.27 \\
\hline $\begin{array}{l}\text { Farmer's perception on improved varieties price } \\
\text { (high/low price) }\end{array}$ & $-0.024 * * *$ & 0.017 & -1.38 \\
\hline Social participation (participant/not & 0.023 & 0.017 & 1.38 \\
\hline Cosmopolitans (movable/not) & 0.015 & 0.016 & 0.88 \\
\hline Access to coffee market information (yes/no) & 0.0036 & 0.0139 & 0.26 \\
\hline The dependency ratio & $0.155^{* * *}$ & 0.026 & 7.50 \\
\hline Constant & $0.6611 * * *$ & 0.053 & 12.45 \\
\hline Sigma & 0.0875 & 0.0053 & 16.36 \\
\hline \multicolumn{4}{|c|}{ 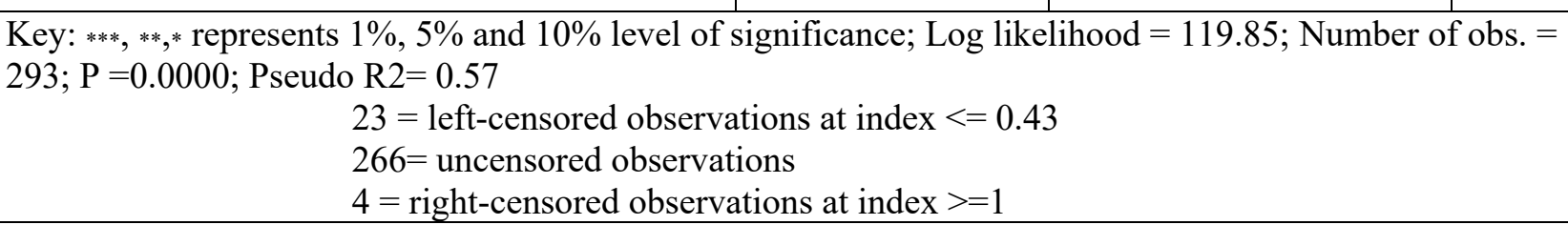 } \\
\hline
\end{tabular}




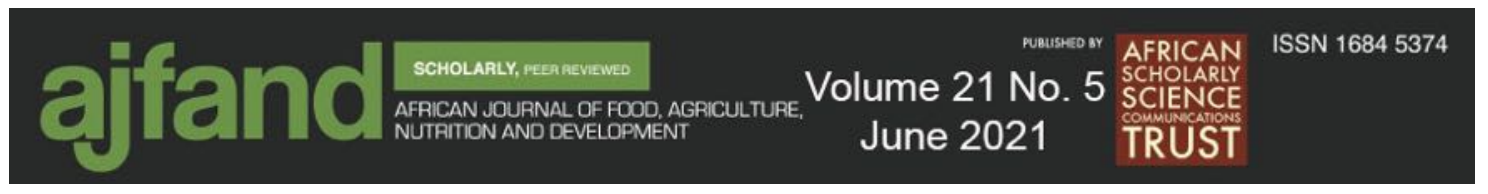

\section{REFERENCES}

1. Bacon C Confronting the coffee crisis: Can Fair Trade, organic, and specialty coffees reduce small-scale farmer vulnerability in Northern Nicaragua? World Dev., 2005; vol. 33( 3): 497-511 https://doi.org/10.1016/j.worlddev.2004.10.002

2. Ebisa DB Impacts of climate change on global coffee production industry: Review, African J. Agric. Res., 2017; vol 12 (19): 1607-1611, 2017 https://doi.org/10.5897/ajar2017.12147

3. Davis AP, Gole TW, Baena $\mathbf{S}$ and $\mathbf{J}$ Moat The Impact of Climate Change on Indigenous Arabica Coffee (Coffea arabica): Predicting Future Trends and Identifying Priorities, PLoS One, 2012; vol 7 (11): 10-14, https://doi.org/10.1371/journal.pone.0047981

4. USDA. Foreign Agricultural Service, Coffee: World Markets and Trade, Coffee World Mark. Trade. 2019; 1-9.

5. Gray Q USDA STAFF AND NOT NECESSARILY STATEMENTS OF OFFICIAL U . S . GOVERNMENT Ethiopia Coffee Annual Coffee Annual Report . 2013; 1-9.

6. Dubale $\mathbf{P}$ and $\mathbf{T}$ Demel Need for forest coffee germplasm conservation and its significance in the control of coffee diseases, 2000.

7. Davis A and J Moat "Coffee Farming and Climate Change in Ethiopia: Impacts, Forecasts, Resilience and Opportunities". 2017; 37.

8. Joskow J and T Yamane "Statistics, an Introductory Analysis.," J. Am. Stat. Assoc.1965; vol. 60 (310) : 678, , doi: 10.2307/2282703.

9. Degnet A, Kassa B and A Waktola Adoption of high yielding varieties of economics, 2001.

10. Mulugeta A Determinants of Intensity of Adoption of Old Coffee Stumping Technology in Dale Wereda, SNNPRS, Ethiopia, MSc Thesis. 2009; 115.

11. Admassie A and G Ayele "Adoption of improved technology" in Ethiopia, Ethiop. J. Econ. 2011; vol. 19 (1): 155-180

https://doi.org/10.4314/eje.v19i1.71416

12. Sisay D Agricultural technology adoption, crop diversification and efficiency of maize-dominated smallholder farming system in Jimma zone" South-Western Ethiopia, 2016.

13. Belay W Determinants of adoption of improved wheat technology in Case of Gozzamen District, East Gojjam in Amhara Regional State, 2017. 


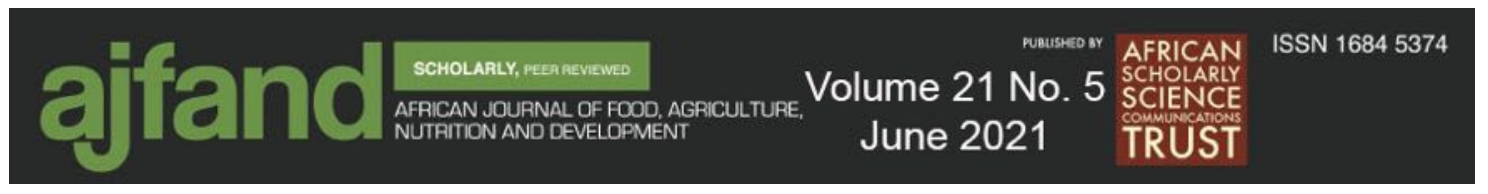

14. Rahmeto N Determinants of adoption of improved haricot bean production package in Alaba special woreda, Southern Ethiopia., MSc Thesis. 2007; 137.

15. Grimachew $\mathbf{S}$ Determinants of Adoption of soil and water conservations practices in the environments of Semen-Mountains National Parks of Ethiopia, 2005.

16. Hailu B Adoption of improved teff and wheat production technologies in croplivestock mixed systems in northern and western Shewa zones of Ethiopia, 2008.

17. Kidane $\mathbf{G}$ Factors Influencing the Adoption of New Wheat and Maize Varieties in Tigray, Ethiopia: The Case of Hawzien Woreda. M.S.C. Thesis Presented To School Of Graduate Studies Of Alemaya University, Ethiopia. 2001; 140. 